\title{
INVESTIGACIÓN/RESEARCH
}

\section{LA REPRESENTACIÓN DE LOS PERSONAJES INMIGRANTES EN LOS PROGRAMAS DE FICCIÓN}

\author{
María Marcos Ramos: Universidad de Salamanca (España) \\ mariamarcos@usal.es
}

Juan José Igartua Perosanz. Universidad de Salamanca. España jigartua@usal.es

Francisco Javier Frutos Esteban. Universidad de Salamanca. España

frutos@usal.es

Isabel Matilde Barrios Vicente. Universidad de Salamanca. España $\underline{\text { imbv@usal.es }}$

Félix Ortega Mohedano. Universidad de Salamanca. España

fortega@usal.es

Valeriano Piñeiro Naval. Universidad de Salamanca. España

vale.naval@usal.es

\section{RESUMEN}

En la presente investigación se ha analizado la imagen de la inmigración en la ficción televisiva, tomando como referencia la Teoría del Cultivo y la investigación previa sobre el análisis de la representación de las minorías étnicas e inmigrantes en la ficción televisiva (Greenberg, Mastro y Brand, 2002). El presente artículo presenta los resultados a los que se ha llegado tras realizar un análisis de contenido a más de 2.000 personajes y más de 100 programas emitidos en horario de prime time en seis

\footnotetext{
1 María Marcos Ramos: es licenciada en Comunicación Audiovisual por la Universidad del País Vasco y doctora en Comunicación Audiovisual en la Universidad de Salamanca. Sus líneas de investigación actuales son la alfabetización mediática, la ficción cinematográfica y la imagen de los inmigrantes en la ficción nacional, tema sobre el que ha realizado su tesis doctoral
} 
cadenas televisivas. Los resultados han permitido concluir que existe una infrarepresentación de los personajes inmigrantes, así como una construcción basada en el uso de estereotipos.

PALABRAS CLAVE: inmigración- ficción televisiva- prime time-análisis de contenido.

\title{
THE REPRESENTATION OF THE IMMIGRANT CHARACTERS IN THE PROGRAMS OF FICTION.
}

\begin{abstract}
This article presents the results of a research study into the image of immigration as presented in television fiction after realizing an analysis of content to more than 2.000 characters and more than 100 programs of prime-time fictional programming broadcast in 2011 on six television channel. The results have allowed to conclude that there exists an infrarepresentación of the immigrant characters, as well as a construction based on the use of stereotypes.
\end{abstract}

KEY WORDS: Immigration-television fiction- content analysis-prime time

\section{INTRODUCCIÓN}

Según las encuestas realizadas por el CIS y los diferentes barómetros, la inmigración es uno de los temas que más preocupa a los españoles. España, además, se ha convertido de manera reciente en un país de inmigración ${ }^{2}$ (Díez Nicolás, 2004). Aunque esta situación está cambiando con la crisis económica en la que se haya inmerso el país ${ }^{3}$, sigue habiendo un volumen importante de población inmigrante ${ }^{4}$.

\footnotetext{
2 Para nuestro estudio, entenderemos por inmigrantes a todas las personas que han dejado su país natal para establecerse en otro de manera permanente sea cuales sean los motivos. Así, un exiliado político, por ejemplo, será considerado inmigrante para el estudio.

3 Según los últimos datos del Instituto Nacional de Estadística (INE, 2011), la población española se reducirá en cerca de medio millón de personas $(-1,23 \%)$ en la próxima década debido a la menor afluencia de población inmigrante al país. A modo de ejemplo, desde enero 2010 han llegado 317.491 inmigrantes, pero han salido del país 356.692 habitantes.

4 Según el INE (2011), a fecha de 1 enero de 2011, el total de residentes en España es de 47.150.819 habitantes. De este total, 41.420.152 tienen nacionalidad española y 5.730 .667 son extranjeros, lo que representa el 12,2\% del total de inscritos. En el año 2013 (INE, 2013), de los 46.704 .314 habitantes que hay en España, 41.586.202 tienen nacionalidad española y 5.118.112 son extranjeros, es decir, el número de inmigrantes residentes en el país representa el $10.95 \%$ de los censados. Los datos con los que se trabajará en el presente trabajo de investigación serán los del 2011, ya que de esta manera se
} 
Si tenemos en cuenta que nuestra percepción del mundo se construye, en parte, gracias a los medios de comunicación, se hace imprescindible analizar qué imagen nos ofrecen sobre este fenómeno reciente en España (van Dijk, 1997, 2003). El análisis de los inmigrantes en los medios informativos ha sido un tema recurrente de estudio en los últimos años (Dixon y Linz, 2000; Entman, 1992; Igartua, Muñiz y Cheng, 2005; Igartua, Muñiz, Otero y de la Fuente, 2007; Romer, Jamieson y De Coteau, 1998; van Dijk, 1989). Las investigaciones que se han realizado sobre inmigración y minorías étnicas se han centrado en la cobertura y tratamiento informativo, señalando que son uno de los factores causantes del incremento de la xenofobia en el país (Igartua, Cheng, Moral, Fernández, Frutos, Gómez-Isla y Otero, 2008; Igartua y Cheng, 2009). La representación de la inmigración en los medios de comunicación, en especial en la prensa escrita y en los formatos informativos televisivos, ha sido un tema bastante estudiado por las Ciencias Sociales (Dixon y Linz, 2000; Entman, 1992; Igartua, Muñiz y Cheng, 2005; Igartua, Muñiz, Otero y de la Fuente, 2007; Igartua, Moral y Fernández, 2011; Igartua; Muñiz, Otero, de la Fuente, 2013; Romer, Jamieson y De Coteau, 1998; van Dijk, 1989). Las conclusiones a las que estos estudios han llegado es que la imagen del inmigrante y las minorías étnicas está asociada a amenazas socioeconómicas y culturales, la aberración, la delincuencia y la violencia en los medios de comunicación (Cea D’ Ancona, 2004 o van Dijk, 1997). Esto es debido a que los medios de comunicación se basan en estereotipos para representar a los inmigrantes, lo que genera en los receptores representaciones sobre la inmigración estereotipadas y cargadas de prejucios.

Desde las Ciencias Sociales se han realizado numerosas investigaciones sobre el tratamiento informativo de la inmigración en los medios de comunicación y sus efectos socio-cognitivos. Los estudios han indicado que son más numerosas las noticias sobre inmigración negativas frente a las positivas, por ejemplo, la contribución positiva de la inmigración para los países de acogida y, además, se tiende a vincular la inmigración con la delincuencia, el crimen y otros problemas sociales (Igartua, Muñiz y Cheng, 2005; Igartua, Muñiz, Otero y de la Fuente, 2007; Igartua, Moral y Fernández, 2011; van Dijk, 1989; Van Gorp, 2005). En este sentido, van Dijk (1994, 1997), a modo de ejemplo, defiende que los inmigrantes, refugiados y minorías étnicas están asociados cada vez más en los medios de comunicación con las amenazas socioeconómicas y culturales, con la desviación, la delincuencia y la violencia ${ }^{5}$.

Por otra parte, las investigaciones realizadas sobre los efectos socio-cognitivos de los encuadres de las noticias sobre el tema -el tratamiento realizado por parte de los

podrá comparar la demografía audiovisual con la real.

5 De este modo, los medios fomentan la creación de una especie de correlación ilusoria, al asociar a las minorías étnicas con acontecimientos de carácter negativo a través de una "estrategia discursiva" establecida en tres etapas. En la primera se realiza una polarización general entre "nosotros" y "ellos". En la segunda se mantiene una predilección por una variedad de "problemas" de los cuales son acusados los inmigrantes (culpabilización de la víctima), y finalmente, en la tercera los medios toman preferencia por un pequeño conjunto de temas negativos (planteando la inmigración como invasión, ataque o amenaza y asociándola a violencia, terrorismo y/o desintegración social) (Muñiz e Igartua, 2004). 
medios de comunicación- han señalado que estos influyen en la percepción, las actitudes y las creencias que sobre la inmigración hay en el país receptor (Brader, Valentino y Suhay, 2008; Domke, McCoy y Torres, 1999; Igartua y Cheng, 2009; Igartua, Moral y Fernández, 2011). Una de las principales consecuencias de este tratamiento informativo es la creación y/o mantenimiento de determinados estereotipos $^{6}$ y prejuicios sobre los inmigrantes. En este sentido, Seiter (1986) ha señalado que los medios de comunicación, en especial la televisión, participan activamente en la generación de estereotipos.

No ha sido objeto de análisis, o al menos de una manera tan extensiva, la imagen de la inmigración en la ficción televisiva, siendo en España prácticamente inexistentes la realización de estudios sobre esta temática, a pesar de ser un componente básico de la programación de las cadenas de televisión en horario de prime time (Ruiz-Collantes, Ferrés, Obradors, Pujadas y Pérez, 2006; Galán, 2006; Lacalle, 2008). Utilizando la técnica del análisis de contenido, con la que "se procede a la observación y al estudio de los estereotipos y representación de los inmigrantes" Galán (2006) realizó un estudio pero su marco de estudio se limitó a dos series de gran trayectoria en la ficción nacional: El Comisario y Hospital Central. Entre las conclusiones más importantes se pueden señalar "la representación discriminatoria o sesgada del colectivo de inmigrantes que aparece en las series elegidas” (Galán, 2006).

Lacalle (2004) ha señalado que los inmigrantes, hasta aproximadamente el año 2003, apenas aparecían en la ficción española y, si lo hacían, solían estar caracterizados como personajes secundarios y asociados a estereotipos negativos, realizando papeles de amigos de algún protagonista principal, ocupando siempre una posición circunstancial y pasiva. Las profesiones que desempeñaban suelen estar relacionadas con el sector servicios, en el mundo del espectáculo o asociados a trabajos domésticos y actividades ilegales. En un estudio realizado con posterioridad, Lacalle (2008) indicó que en la ficción nacional predominaba el inmigrante en situación irregular, con baja cualificación. Se daba una alta presencia de inmigrantes que actúan como criminales o son víctimas de delitos o acciones violentas; y, era infrecuente la presencia de inmigrantes cualificados o que desarrollasen un papel central en las tramas narrativas de las series analizadas. La imagen que se da en la ficción nacional según Ruiz-Collantes, Ferrés, Obradors, Pujadas y Pérez (2006) es la de personajes no protagónicos, cuya representación es mayoritariamente negativa, asociados a problemas y victimización. Además, como no son capaces de conseguir los objetivos que se proponen, tienden a la simulación, la manipulación o el engaño.

Los estudios de Ruiz-Collantes, Ferrés, Obradors, Pujadas y Pérez (2006) y Lacalle (2008) se centraron en el análisis de los personajes inmigrantes/extranjeros en la ficción nacional, mientras que el presente estudio tiene en cuenta toda la programación de ficción emitida en prime time, independientemente de su origen

6 Los estereotipos son creencias sociales que se basan en la generalización sobre las características de un grupo, y al tiempo que se manifiesta un rechazo de las diferencias individuales. 
nacional y del género -analizándose series y largometrajes-. Ambos autores utilizaron un enfoque de carácter cualitativo, observando únicamente los personajes inmigrantes/extranjeros, sus características físicas y psicológicas, pero no las relaciones que se establecían con otros personajes.

La investigación que aquí se presenta estudió una muestra de programación relativamente amplia utilizando el análisis de contenido como método de investigación, lo que permite realizar un análisis socio-demográfico de los personajes de la ficción televisiva emitida en las cadenas nacionales en prime time. No se observó el personaje inmigrante/extranjero de forma aislada, sino que se consideraron las relaciones que establecían con los personajes autóctonos/nacionales, realizando comparaciones entre ambos. Así, se pudieron extraer conclusiones sobre cómo se representaban los personajes inmigrantes, estrategia que ha sido utilizada en los estudios previos revisados sobre la imagen de las minorías étnicas en la ficción televisiva (por ejemplo, Mastro y Greenberg, 2000 y Harwood y Anderson, 2002). Se tuvo en cuenta para realizar este estudio las investigaciones sobre la imagen o representación de los inmigrantes y de las minorías étnicas -especialmente afroamericanos y latinos- en la ficción televisiva, y las investigaciones previas sobre el análisis de los encuadres noticiosos de la inmigración. Se establecieron las siguientes hipótesis:

H1.- Se espera encontrar una infra-representación de los personajes inmigrantes/extranjeros en la programación de ficción emitida en el horario de prime time en televisión, en comparación con los personajes nacionales/autóctonos.

H2.- Los personajes inmigrantes/extranjeros, en comparación con los personajes autóctonos/nacionales, ocuparán en mayor medida papeles secundarios o de background y en menor medida aparecerán como personajes principales.

H3.- Habrá una mayor frecuencia de personajes antagónicos o villanos, de secundarios protagónicos y de secundarios no protagónicos, y menos de protagonistas, entre los personajes inmigrantes/extranjeros, en comparación con los autóctonos/nacionales.

H4.- Los personajes inmigrantes/extranjeros, en comparación con los personajes autóctonos/nacionales, tendrán un menor nivel de estudios, un menor nivel socio-económico y desempeñarán profesiones de menor cualificación.

H5.- Se observarán diferencias significativas entre los personajes inmigrantes/extranjeros, en comparación con los autóctonos/nacionales, en la manifestación de comportamientos violentos, victimización, problemas de salud, temas de conversación y rasgos de personalidad. 
Inmigración- ficción televisiva- prime time-análisis de contenido.

\section{METODOLOGÍA}

El método de trabajo que se utilizó es el análisis de contenido, que "comprende procedimientos especiales para el procesamiento de datos científicos" (Krippendorff, 1990, p. 28) y permite cuantificar datos y aportar conclusiones objetivas, apoyadas en números que representan fenómenos reales. Tal y como afirma Juan José Igartua (2006, p. 180),

el análisis de contenido está presente en aquellos trabajos que necesitan aproximarse de manera científica al análisis de los mensajes (cualquiera que fuera su naturaleza), comprender su génesis o proceso de formación, obtener descripciones precisas de su estructura y componentes, analizar su flujo o patrones de intercambio, trazar su evolución e inferir su impacto.

Utilizar como técnica de investigación el análisis de contenido es muy útil y necesario en las Ciencias Sociales ya que permite "formular, a partir de ciertos datos, inferencias reproducibles y válidas que puedan aplicarse a su contexto" (Krippendorff, 1990, p. 28). Así mismo, comprende los datos no como acontecimientos físicos sino como fenómenos simbólicos. Por tanto, el análisis de contenido se ha convertido en una de las técnicas más utilizadas en este campo.

Utilizar para este estudio este método resultó fundamental ya que de esta manera se analizaron a los personajes como unidad básica y permitió que se trabajasen diferentes aspectos en los otros estudios realizados.

De este modo, fueron unidades de registro, o de significación como señala Bardin tanto el programa en su conjunto como los personajes ya que son "el segmento de contenido que será necesario considerar como base con miras a la categorización y al recuento frecuencial" (Bardin, 1996, p. 79). Es en este paso en dónde se miden las variables, donde se atribuyen números a las manifestaciones de la unidad de análisis. Además, hay que "someter estos números a ciertas técnicas matemáticas" (Igartua, 2006 , p. 203) que nos permitan extraer conclusiones cuantitativas con las que elaborar teorías tras el análisis de estos datos.

\subsection{Equipamiento técnico}

Para poder disponer de los programas que se han utilizado en este estudio, se ideó un sistema que permitiese grabar de forma simultánea los diferentes canales de televisión utilizados en la muestra en formato digital. El equipo de grabación estaba compuesto por siete receptores TDT provistos de disco duro interno de 1.5 TB de capacidad. Cinco de los TDT eran de marca Energy Sistem modelo P3350 TDT y dos de marca O2. Cada uno de los receptores de TDT se sincronizaba y se grababa con cada una de las cadenas de análisis -La 1, La 2, Antena 3, Cuatro, Telecinco y La 
Sexta-. Además, estos TDT estaban conectados por red a dos ordenadores de alta capacidad $7^{7}$ para poder almacenar cada uno de los archivos. De esta manera, se aseguraba la grabación de los espacios ya que, por un lado, se almacenaban en los discos duros internos de los TDT y, además, en los discos duros internos de los ordenadores. Si fallaba alguno de los sistemas, siempre se podría recurrir al otro.

\subsection{Muestra de contenidos}

Para la muestra se grabaron tres semanas completas de emisión televisiva -31 de enero al 06 de febrero; 11 al 17 de julio y del 26 de septiembre al 01 octubre del 2011de las seis cadenas televisivas generalistas nacionales: La 1, La 2, Antena 3, Cuatro, Telecinco y La Sexta. Estas cadenas suman una cuota de pantalla del $64.70 \%$ según el Estudio General de Medios (AIMC, 2011). La muestra total analizada estaba compuesta por 114 programas y 2.623 personajes.

Los equipos de grabación se programaron para comenzar a grabar a las 20:00 y finalizar a las 02:00 horas. Aunque se grabaron seis horas de programación por día, solamente se analizaron los programas de ficción que se emitían en horario de prime time, esto es, de las 20:00 a las 24:00 horas. A la hora de efectuar la selección de programas, solo se han tenido en cuenta aquellos programas que se emitan entre las 20:00 y las 24:00 horas. No se han tenido en cuenta los programas que hubiesen empezado antes de las 20:00 o después de las 24:00, pero si un programa empiezaba antes de las 24:00 sí se ha analizado aunque su hora de finalización fuese posterior a las 24:00 horas ${ }^{8}$.

Los únicos programas que se analizaron fueron los de ficción: series, seriales, telenovelas, comedias de situación, largometrajes o TV movies. Para determinar qué se entiende por programa ficcional se tuvo en cuenta esta definición: formato destinado al entretenimiento, con una estructura narrativa clara (presentación, conflicto, resolución) y con un elenco de personajes que intervienen en la acción, pudiéndose identificar personajes principales, secundarios y de background. Con el término "ficción" se alude "al hecho de la simulación o ilusión de realidad" (Estébanez Calderón, 2002, p. 411) que se produce en la invención artística -y en este caso audiovisual- al presentar seres y acontecimientos que se desarrollan en un mundo imaginario. Se han descartado, por tanto, los programas informativos, reality shows (como los talk shows) y otros espacios de entretenimiento, como los concursos, programas de humor o aquellos que se basan en la presentación de

7 Los ordenadores con los que se trabajó tenían las siguientes características técnicas: ordenador core 2 duo E7500, memoria RAM 4GB, 1 disco duro 1TB, 1 disco duro 2TB, tarjeta grafica geforce 9400 1CB y grabador dvd. El sistema operativo era Windows 7 PRO.

8 Por ejemplo, si un programa de ficción comenzaba a las 19:55 horas no se analizaba aunque su emisión estuviese dentro del horario a analizar. Sí se ha analizado programas que han comenzado a las 23:55 horas aunque su final estuviese fuera del horario de prime time. Por ejemplo, el programa Escudo humano (La Sexta, 4/01/2011), estaba previsto que comenzase a las 23:59 horas, sin embargo, comenzó más tarde y no fue analizado. Por contra, Los protegidos (Antena 3, 6/01/2011) estaba previsto que comenzase a las 00:02 horas, sin embargo comenzó a las 23:52 horas por lo que sí se analizó. 
sketches ${ }^{9}$, y también la publicidad. Para proceder a la selección de los programas se creó una "ficha de selección de programas" en la que se indicaba a los analistas, mediante una serie de instrucciones, qué programas debían seleccionar: programas de ficción (series, seriales, telenovelas, comedias de situación, largometrajes o TV movies) que tuvieran su hora de inicio entre las 20:00 y las 24:00, así como la información que debían recoger, por ejemplo: hora de inicio, hora de final, día de emisión, etc.

Se identificaron un total de 114 programas y 2.623 personajes. En la semana del 31 de enero al 6 de febrero de 2011 se identificaron 41 programas y 1.005 personajes. En la del 26 de septiembre al 2 de octubre de 2011, 36 programas y 783 personajes. En la última semana de estudio, 11 de julio al 17 de julio de 2011, 37 programas y 835 personajes. Los 114 programas seleccionados totalizaron 8.181 minutos (en torno a 136,35 horas), siendo la duración media de cada programa de 84.27 minutos (DT = 36.42). Los 114 programas analizados se dividían en 43 largometrajes y 71 series.

Tabla 1. Descripción de la muestra analizada

\begin{tabular}{|c|c|c|c|c|}
\hline \multirow[t]{2}{*}{ Semana } & \multicolumn{2}{|c|}{ Programas } & \multicolumn{2}{|c|}{ Personajes } \\
\hline & $N$ & $\%$ & $N$ & $\%$ \\
\hline $\begin{array}{l}\text { - Del } 31 \text { de enero al } 6 \text { de } \\
\text { febrero de } 2011\end{array}$ & 41 & 35.9 & 1005 & 38.3 \\
\hline $\begin{array}{l}\text { - Del } 26 \text { de septiembre al } 2 \\
\text { de octubre de } 2011\end{array}$ & 36 & 31.6 & 783 & 29.8 \\
\hline $\begin{array}{l}\text { - Del } 11 \text { de julio al } 17 \text { de } \\
\text { julio de } 2011\end{array}$ & 37 & 32.5 & 835 & 31.8 \\
\hline$N$ total & 114 & 100 & 2.623 & 100 \\
\hline
\end{tabular}

En los programas identificados como largometrajes, se identificaron 1.283 personajes (un $47.20 \%)$, mientras que en las series fueron 1.385 (52.80\%) (M=1.53; DT=.49), distribuidos tal y como se indica en la tabla por semanas y por tipo de programa.

\footnotetext{
9 Un sketch es una escena cómica que dura entre uno y diez minutos aproximadamente. En ella participan actores o comediantes y puede ser montada en un teatro o transmitida por televisión. Los sketches, que solían usarse en los vodeviles, han sido incorporados a espectáculos de variedades, programas cómicos, entretenimiento para adultos, talk shows y algunos shows infantiles, como Barrio Sésamo. A menudo, el sketch es improvisado por los actores la primera vez que se realiza y el resultado de esto es posteriormente transcrito a modo de libreto. No obstante, la improvisación no se practica necesariamente en todas las ocasiones.
} 
Tabla 2. Descripción de personajes por semana y tipo programa analizados

\begin{tabular}{|c|c|c|c|c|c|}
\hline \multirow[t]{2}{*}{ Semana } & \multicolumn{2}{|c|}{ Largometrajes } & \multicolumn{2}{|c|}{ Series } & \multirow[t]{2}{*}{$N$ total } \\
\hline & $N$ & $\%$ & $N$ & $\%$ & \\
\hline $\begin{array}{l}\text { - Del } 31 \text { de enero al } 6 \text { de febrero } \\
\text { de } 2011\end{array}$ & 453 & 36.5 & 552 & 39.8 & 1.005 \\
\hline 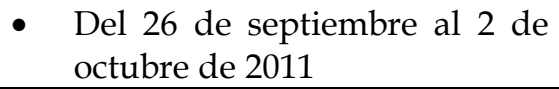 & 403 & 32.5 & 380 & 27.4 & 783 \\
\hline $\begin{array}{l}\text { - Del } 11 \text { de julio al } 17 \text { de julio de } \\
2011\end{array}$ & 382 & 30.8 & 453 & 32.7 & 835 \\
\hline$N$ total & 1.238 & 100 & 1.385 & 100 & 2.623 \\
\hline
\end{tabular}

Tabla 3. Descripción de personajes y programas por cadenas

\begin{tabular}{|l|c|c|c|c|}
\hline \multirow{2}{*}{ Cadenas } & \multicolumn{2}{|c|}{$\mathbf{N}^{\mathbf{0}}$ de programas analizados } & \multicolumn{2}{c|}{$\mathbf{N}^{\mathbf{0}}$ de personajes analizados } \\
\cline { 2 - 5 } & $\mathbf{N}$ & $\mathbf{0}$ & $\mathbf{N}$ & $\mathbf{0}$ \\
\hline La 1 & 15 & 13.1 & 573 & 21.8 \\
\hline La 2 & 18 & 15.7 & 839 & 31.9 \\
\hline Antena 3 & 18 & 15.7 & 413 & 15.7 \\
\hline Cuatro & 19 & 16.6 & 261 & 9.9 \\
\hline Telecinco & 15 & 13.1 & 223 & 8.5 \\
\hline La Sexta & 29 & 25.4 & 314 & 11.9 \\
\hline \multicolumn{1}{|c}{$\boldsymbol{N}$ Total } & $\mathbf{1 1 4}$ & $\mathbf{1 0 0}$ & $\mathbf{2 . 6 2 3}$ & $\mathbf{1 0 0}$ \\
\hline
\end{tabular}

El día en que menos personajes se analizaron en las tres semanas fue el 15 de julio de 2011 con 53, frente a los 215 -número máximo de personajes analizados por día- del 16 de julio de 2011. El día que menos programas se analizaron fue el 17 de julio de 2011 con dos programas y el que más, fueron el 31 de enero de 2011, 13 de julio de 2011 y el 26 de septiembre de 2011, con ocho programas. La relación de personajes de la muestra por día se puede ver en la siguiente tabla.

Tabla 4. Descripción de personajes y programas por días analizados

\begin{tabular}{|c|c|c|c|c|}
\hline \multirow[t]{2}{*}{ Día en fecha } & \multicolumn{2}{|c|}{ Personajes } & \multicolumn{2}{|c|}{ Programas } \\
\hline & $N$ & $\%$ & $N$ & $\%$ \\
\hline - $31 / 01 / 2011$ & 192 & 7.3 & 8 & 7 \\
\hline - $01 / 02 / 2011$ & 162 & 6.2 & 7 & 6.1 \\
\hline - $02 / 02 / 2011$ & 148 & 5.6 & 5 & 4.4 \\
\hline $\begin{array}{ll} & 03 / 02 / 2011 \\
\end{array}$ & 156 & 5.9 & 6 & 5.3 \\
\hline - $\quad 04 / 02 / 2011$ & 102 & 3.9 & 5 & 4.4 \\
\hline - $\quad 05 / 02 / 2011$ & 160 & 6.1 & 6 & 5.3 \\
\hline - $\quad 06 / 02 / 2011$ & 85 & 3.2 & 4 & 3.5 \\
\hline - $11 / 07 / 2011$ & 119 & 4.5 & 7 & 6.1 \\
\hline • $12 / 07 / 2011$ & 103 & 3.9 & 5 & 4.4 \\
\hline - $13 / 07 / 2011$ & 170 & 6.5 & 8 & 7 \\
\hline
\end{tabular}


Inmigración- ficción televisiva- prime time-análisis de contenido.

\begin{tabular}{|c|c|c|c|c|}
\hline - $14 / 07 / 2011$ & 109 & 4.2 & 5 & 4.4 \\
\hline - $15 / 07 / 2011$ & 53 & 2.0 & 3 & 2.6 \\
\hline - $16 / 07 / 2011$ & 215 & 8.2 & 7 & 6.1 \\
\hline - $17 / 07 / 2011$ & 66 & 2.5 & 2 & 1.8 \\
\hline - 26/09/2011 & 174 & 6.6 & 8 & 7 \\
\hline - 27/09/2011 & 126 & 4.8 & 5 & 4.4 \\
\hline - $28 / 09 / 2011$ & 79 & 3.0 & 4 & 3.5 \\
\hline - 29/09/2011 & 139 & 5.3 & 6 & 5.3 \\
\hline - $30 / 09 / 2011$ & 65 & 2.5 & 4 & 3.5 \\
\hline - $01 / 10 / 2011$ & 137 & 5.2 & 6 & 5.3 \\
\hline $\begin{array}{ll}\text { - } 02 / 10 / 2011 \\
\end{array}$ & 63 & 2.4 & 3 & 2.6 \\
\hline$N$ total & 2.623 & 100 & 114 & 100 \\
\hline
\end{tabular}

Si tenemos en cuenta los datos de los 114 programas que forman parte de la muestra de este estudio, el programa que menos audiencia tiene es Criando malvas: jvaya pájaro! (La 2,6/02/2011), con un share del 1.8\% y el que más audiencia ha tenido de la muestra con un $29.3 \%$ es Águila roja: La puerta misterios (La 1, 26/09/2011), por lo que el rango de la muestra es de 27.5. La audiencia media de todos los programas de la muestra es de 8.96 (DT=5.33). Teniendo en cuenta el origen de la producción, la audiencia media de los programas nacionales es superior al de la muestra, con 10.78 $(\mathrm{DT}=6.66)$, siendo el programa nacional con menos audiencia un largometraje Caminos cruzados (La 2, 11/07/2011)- de coproducción española, francesa e italiana, que obtuvo un 1.90 de share y el que mayor audiencia tuvo fue el espacio anteriormente mencionado de Águila roja: La puerta misterios (La 1, 26/09/2011). Si se analizan los espacios de la muestra realizados en EE.UU. el que menor audiencia he tenido es el mencionado Criando malvas: jvaya pájaro! (La 2,6/02/2011) y el que más, con un 21.5\%, es la película La búsqueda (La 1,6/02/2011). La audiencia media de los programas estadounidenses es inferior a la nacional, con un 8.41 (DT=4.28). En lo que respecta a los programas realizados en otro país de Europa diferente a España, la audiencia media es menor a las anteriores $(\mathrm{M}=3.56$, DT=0.75). Entre los programas analizados en esta categoría, el espacio con menor audiencia es la película La condesa rusa (La 2, 29/09/2011) con un $2.80 \%$ de audiencia. El programa con mayor índice de audiencia en esta categoría, con un $4.30 \%$, es la película Días de gloria (La 2, 3/02/2011).

Habría que destacar, a la vista de estos datos, que los programas de ficción nacional han tenido mejores índices de audiencia, tal y como evidencia el share de la serie Águila roja: La puerta misterios (La 1, 26/09/2011), que es el mayor de los 114 programas de la muestra. Además, analizando la ficción en función del origen de la producción también destaca la ficción nacional, con una media superior a la estadounidense y a la ficción realizada en otro país de Europa diferente a España.

\subsection{Libro de códigos}

Para el análisis de los programas de ficción y de sus personajes, se utilizó un libro de códigos elaborado a partir de los estudios desarrollados por Harwood y Anderson (2002), Igartua, del Río, Álvarez y del Río (1998), Igartua, Barrios y Ortega (2012), 
Koeman, Peeters y D’Haenes (2007), Mastro y Greenberg (2000), Mastro y BehmMorawitz (2005), Neuendorf (2002) y Potter y Warren (1998).

En la investigación que nos ocupa se establecieron diez grandes grupos de variables que a su vez se dividieron en otras variables y categorías que aportaban datos fundamentales con los que analizar la noticia. Los diez grandes grupos de variables son:

1. Datos de identificación básicos. Se evaluaron los siguientes aspectos: número del personaje, número de programa, número de codificador, fecha de emisión del programa, día de la semana de emisión y la cadena de televisión de emisión del programa.

2. Datos referidos al programa. Este apartado integraba las siguientes variables: a) origen de la producción ( $0=$ no identificado, $1=$ origen nacional, España, $2=$ Estados Unidos, 3 = otro país europeo, 4 = América Latina, 5 = otro país); b) tipo de programa ( 1 = película largometraje, 2 = serie, serial, comedia de situación, miniserie o serie procedimental como CSI, House o Bones); c) duración del programa (en minutos, excluyendo la publicidad); y, d) lugar en el que se desarrollaba la acción principal dentro del programa (1 = España, 2 = otro país de Europa, 3 = Estados Unidos, $4=$ América Latina, 5 = otro lugar).

3. Aspectos narrativos del personaje. Se evaluaron dos aspectos. El tipo de personaje (Mastro y Greenberg, 2000) se evaluó mediante el siguiente código: 1 = principal (su presencia es esencial para el desarrollo de la línea narrativa), 2 = secundario (están envueltos en la línea narrativa del programa, pero no son esenciales en la misma), 3 = background (tienen una presencia no esencial, periférica, o aparecen en el programa de manera muy episódica).

El rol narrativo del personaje en el programa se evaluó mediante el siguiente código: 1 = protagonista (es quien realiza las acciones más importantes de la historia; la estructura dramática descansa sobre él y sus acciones); 2 = antagonista o villano (personaje principal que se opone a las acciones del protagonista); 3 = secundario protagónico (son aquellos que están estrechamente relacionados con el personaje principal; su participación dentro de la historia es importante y sus acciones son dirigidas en la misma dirección que las acciones del protagonista); 4 = secundario no protagónico (su participación dentro de la historia no es tan relevante, dado que tiene una presencia no esencial y que no se relaciona estrechamente con ningún personaje protagonista ni antagonista).

4. Aspectos socio-demográficos del personaje. Se evaluaron las siguientes variables centradas en el personaje: a) sexo ( 1 = masculino, 2 = femenino), b) grupo de edad ( 1 = niño, entre 0 y 12 años; 2 = adolescente, entre 13 y 17 años; 3 = adulto joven, entre 18 y 30 años; 4 = adulto, entre 31 y 64 años; 5 = anciano, más de 65 años); c) nivel de estudios $(0=$ no se puede identificar; 1 = analfabeto, no sabe leer ni escribir; 2 = sin estudios; 3 = primarios, 4 = secundarios, ESO, Bachillerato o FP; 5 = universitarios); 
d) nivel socio-económico ( $0=$ no se puede identificar; 1 = bajo, es un personaje de clase obrera o clase baja, que no cubre satisfactoriamente sus necesidades básicas con sus ingresos económicos; 2 = medio, un personaje que trabaja para vivir, tiene cubiertas sus necesidades y se puede permitir algunos pequeños lujos; $3=$ alto, un personaje que no depende de su trabajo para mantener su nivel de vida o que tiene un trabajo que le permite disfrutar de muchos lujos no accesibles para la mayoría); e) la ocupación laboral se codificó a partir de un listado establecido por el Centro de Investigaciones Sociológicas (CIS) de España para analizar profesiones (se incluían 18 profesiones distintas, más la categoría $0=$ no se puede identificar).

Un aspecto relevante del presente estudio fue la evaluación de la nacionalidad del personaje. Dado que en muchas ocasiones será difícil discernir el lugar de nacimiento del personaje, la identificación de este criterio se realizó a partir de un conjunto de rasgos o atributos que debían ser evaluados conjuntamente o de forma separada: a) el lugar de nacimiento del personaje (siempre que hubieran menciones explícitas sobre este aspecto en el programa); b) el lugar de nacimiento de uno de los progenitores del personaje, ya que se contemplaba la posibilidad de ser "inmigrante de segunda generación" (cuando al menos uno de los progenitores había nacido fuera del país); c) características biológicas o rasgos fenotípicos (como la forma de los ojos, el color de la piel y el tipo de peinado); d) características culturales (como el modo de vestir, el nombre del personaje o el acento en el habla); y e) la motivación para estar en otro país (laboral, estudios, vacaciones). La valoración de la nacionalidad se realizó siempre teniendo en cuenta el país en el que se desarrollaba la acción durante la mayor parte del tiempo narrativo. Tomando como referencia los criterios mencionados, se utilizó el siguiente código para clasificar la nacionalidad del personaje: $0=$ no identificable claramente; $1=$ nacional del país en donde se desarrollaba la acción principal en la narración (autóctono, si reside en su país de procedencia); 2 = extranjero, aquella persona que procede de otro país diferente al que reside pero que está en el país extranjero de forma pasajera o transitoria (por estudios, vacaciones o negocios); 3 = inmigrante, es aquel que abandona su país de origen y llega a otro país para establecerse en él y con un proyecto laboral concreto; también se codificó como "inmigrante" (de segunda generación) cuando al menos uno de los progenitores del personaje analizado no había nacido en el país en el que se desarrollaba la acción principal y se había establecido en otro país por una motivación laboral.

5. Comportamientos violentos del personaje. Con una escala dicotómica $(0=$ no; $1=$ sí) se codificó el grado de presencia de diferentes tipos de comportamiento o modos de violencia, a partir de la clasificación de Potter y Warren (1998): a) realización o ejecución de "ataques físicos mayores"; b) realización o ejecución de "ataques físicos menores"; c) realización o ejecución de actos que provocan "daños a la propiedad"; d) realización o ejecución de actos de "intimidación"; y, e) realización de "comentarios hostiles". Se creó un índice de comportamiento violento $(a=.66)$ a partir de la suma de las cinco variables señaladas. 
6. Comportamientos violentos dirigidos contra el personaje. Con una escala de dicotómica ( 0 = no; 1 = sí), y partiendo de la clasificación de Potter y Warren (1998), se codificó si el personaje analizado sufría o era víctima de los siguientes tipos o modos de violencia: a) ataques físicos mayores; b) ataques físicos menores; c) actos que provocan daños a la propiedad; d) actos de intimidación; y, e) comentarios hostiles. Se creó un índice de victimización del personaje $(\alpha=.59)$ a partir de la suma de las cinco variables señaladas.

7. Comportamientos problemáticos de salud manifestados por el personaje. Se codificó (1 = sí, 0 = no), si el personaje analizado: a) bebía o tomaba alcohol; b) fumaba tabaco; c) tomaba fármacos; d) consumía drogas ilegales; y, e) si presentaba una conducta alimentaria problemática. Se creó un índice de problemas de salud a partir de la suma de las cinco variables señaladas (a de Cronbach $=.29$ ).

8. Temas de conversación desplegados por el personaje. Se codificó de manera dicotómica $(0=$ no, 1 = sí), si el personaje conversaba con otros personajes, en alguna ocasión a lo largo del programa, sobre los siguientes temas: amor, violencia, amistad, sexo, dinero, diferencias sociales, trabajo, medio ambiente, salud, educación, familia, política, deporte, racismo e inmigración. Se creó un índice de riqueza conversacional del personaje a partir de la suma de las quince variables señaladas ( $a$ de Cronbach $=$ .67).

10. Rasgos de personalidad del personaje. Tomando como referencia el estudio de Igartua, del Río, Álvarez et al, (1998) se evaluó, mediante una escala de tres puntos (0 $=$ no es característico del personaje; 1 = define parcial o moderadamente la personalidad del personaje; 2 = define perfectamente la personalidad del personaje) en qué medida los siguientes rasgos caracterizaban la personalidad del personaje analizado: amistoso, abierto (extrovertido), bueno (de buen corazón), desleal, injusto, traicionero, agresivo, inteligente, trabajador, desconfiado, agradecido, conflictivo, racista y tolerante. A partir de estas variables se crearon dos índices: índice de rasgos positivos de personalidad ( $a$ de Cronbach $=.88$ ) e índice de rasgos negativos de personalidad (a de Cronbach $=.78$ ).

\subsection{Codificación y fiabilidad}

Dado que el siguiente paso, el de la codificación, es uno de los más importantes, "debe efectuarse de manera sistemática" (Igartua, 2006, p. 212), ya que uno de los objetivos del análisis de contenido es que pueda ser reproductible, es decir, que "cualquier analista que repita el proceso debe llegar a las mismas conclusiones" (Igartua, 2006, p. 212). Resulta fundamental que todos los analistas hayan interiorizado cada una de las variables y categorías, que entiendan lo mismo y que comprendan perfectamente el proceso. Tal y como indica Krippendorff (1990, p. 104), "los observadores, codificadores y jueces deben estar familiarizados con la naturaleza del material que han de registrar, pero además deben ser capaces de manejar fiablemente las categorías y términos que componen el lenguaje de datos. No es fácil cumplir con este doble requisito". 
Así, una vez concluida la fase de codificación de la muestra total del año 2011, se realizó un análisis sobre un $11.4 \%$ de los programas y un 10.8 \% de los personajes ( $n=13$, con 284 personajes) de la muestra total para calcular la fiabilidad del proceso de codificación. Para ello se utilizó, como en el estudio piloto realizado, el coeficiente de acuerdo observado (AO) y el Alpha de Krippendorff $\left(a_{k}\right)$ (Igartua, 2006).

Si se tienen en cuenta las 68 variables consideradas, la media en el índice de acuerdo observado (AO) fue de .87, mientras que la media que se obtuvo en el coeficiente Kalpha de Krippendorff fue de $a_{k}=.53$.

Dos de las variables más importantes y sensibles para el estudio son la nacionalidad y lugar en el que se desarrolla la acción, ya que permiten determinar el número de autóctonos/nacionales e inmigrantes/extranjeros a analizar en la investigación, por lo que era de vital importancia que presentasen unos valores suficientemente altos en los índices de fiabilidad intercodificadores. Con los índices que arrojan, la muestra se considera fiable: la variable "nacionalidad" arrojó un valor muy aceptable $(\mathrm{AO}=.95$, $\left.\mathrm{a}_{\mathrm{k}}=.80\right)$ y también la variable "lugar en el que se desarrollaba la acción principal en el programa" $\left(\mathrm{AO}=.87, \mathrm{a}_{\mathrm{k}}=.95\right)$.

De las 68 variables analizadas un 35.2\% están por encima del .90, lo que indica que la fiabilidad intercodificadores ofrece buenos índices. Si bien es cierto que las variables personalidad, de corte más subjetivo, fueron las que arrojaron valores de fiabilidad intercodificadores más bajos, por lo que los resultados relativos a dichas variables conviene interpretarlos con cautela (Neuendorf, 2002).

\section{ANÁLISIS Y DISCUSIÓN}

\subsection{Hipótesis 1: perfil de los personajes televisivos en función de la nacionalidad y procedencia geográfica}

Esta hipótesis trataba de analizar si existía el mismo porcentaje de población extranjera en la ficción nacional que la que figura en los registros oficiales en la sociedad española. Dado que la ficción que se analizó fue la emitida en el año 2011, se contrastará con los datos del INE de ese mismo año.

Tras analizar la nacionalidad de los personajes de la muestra realizada ${ }^{10}$, se identificaron un $87.6 \%$ de personajes nacionales, esto es, personajes nacidos en el mismo país en el que se encuentra situada la trama de la ficción. En cuanto a los personajes inmigrantes -aquel que abandona su país de origen y llega a otro país para establecerse en él y con un proyecto laboral concreto- el porcentaje obtenido en esta muestra fue del $4.6 \%$ y en cuanto a los personajes extranjeros -aquella persona que procede de otro país diferente al que reside pero que está en el país extranjero de

10 A partir de aquí la muestra de personajes se reduce a 2.602 ya que 21 personajes no pudieron ser identificados -un $0.8 \%$ - en la variable nacionalidad por lo que la muestra se reduce. Éste será el dato que se tenga en cuenta para los análisis realizados. 
forma pasajera o transitoria, como por estudios, vacaciones o negocios-, el porcentaje fue del $7 \%$, por lo que el total de los personajes inmigrantes/extranjeros es del $11.5 \%$.

Se observó una relación estadísticamente significativa entre el origen del programa y la nacionalidad $(\chi 2[2, N=2602]=129.91, p<.001)^{11}$. Si tenemos en cuenta el origen de la producción, los programas nacionales mostraron la siguiente relación de personajes. El total de personajes analizados en los programas nacionales, esto es, programas realizados en España fue de $942^{12}$ de los cuales 801 eran nacionales, frente a 141 que eran inmigrantes/extranjeros ${ }^{13}$. En cuanto a los programas de otros orígenes geográficos, la relación fue la siguiente. En los programas realizados en EE.UU. los personajes nacionales analizados fueron 1.405 frente a los 108 de inmigrantes/extranjeros que aparecían en los programas analizados. Sin embargo, en los programas analizados de otros países distintos a España y Estados Unidos, el porcentaje de personajes nacionales y el de inmigrantes/extranjeros fue similar entre estas dos variables, con 93 personajes autóctonos/nacionales, frente a los 54 de inmigrantes/extranjeros. En la tabla adjunta se pueden ver estos datos con mayor profundidad.

Tabla 6. Relación entre la nacionalidad del personaje y el origen de la producción del programa en el que interviene (\% columna)

\begin{tabular}{|c|c|c|c|c|}
\hline \multirow[t]{2}{*}{ Nacionalidad del personaje } & \multirow[t]{2}{*}{ Total } & \multicolumn{3}{|c|}{ Origen de la producción del programa } \\
\hline & & $\begin{array}{l}\text { Origen nacional } \\
\text { (España) }\end{array}$ & $\begin{array}{l}\text { Estados } \\
\text { Unidos }\end{array}$ & Otro país \\
\hline - Autóctono/nacional & 88.4 & $85.0-$ & $92.9+$ & $63.3-$ \\
\hline - Inmigrante/extranjero & 11.6 & $15.0+$ & $7.1-$ & $36.7+$ \\
\hline $\bar{N}$ & 2602 & 942 & 1513 & 147 \\
\hline
\end{tabular}

- Valor estadísticamente menor que el porcentaje total (análisis de los residuos tipificados corregidos).

+ Valor estadísticamente mayor que el porcentaje total (análisis de los residuos tipificados corregidos). $\left(\chi^{2}[2, N=2602]=129.91, p<.001\right)$

Para poder realizar una comparación, se revisaron las cifras demográficas para comprobar en qué medida los inmigrantes/extranjeros estaban representados en la ficción. Según los datos ofrecidos por el INE, en el año 2011 vivían en España 47.150.819 habitantes, de los cuales el 12.2\% de la población estaba empadronada como extranjera, lo que supone 5.730 .667 personas. De este modo, si observamos la muestra sin tener en cuenta el origen de la producción el número de personajes nacionales $-88.4 \%$ - y el número de personajes inmigrantes/extranjeros es de $11.5 \%$. Si

11 En contrastes de hipótesis, el valor p está definido como la probabilidad de obtener un resultado al menos tan extremo como el que realmente se ha obtenido (valor del estadístico calculado), suponiendo que la hipótesis nula es cierta. Se rechaza la hipótesis nula si el valor $\mathrm{p}$ asociado al resultado observado es igual o menor que el nivel de significación establecido, convencionalmente 0.05 ó 0.01 . El valor p oscila entre 0 y 1 , de tal manera que valores altos de p no rechazan la hipótesis nula y valores bajos de $\mathrm{p}$ rechazan la $\mathrm{H} 0$.

12 Tan solo seis $(0.73 \%)$ personajes de la muestra total de la ficción nacional no pudieron ser identificados con ninguna nacionalidad.

13 Como en el INE no se distingue entre inmigrantes y extranjeros, como sí se hizo en el estudio a la hora de codificar, para el análisis de los datos se creó una nueva variable en la que se aglutinaran estas dos variables. 
se tiene en cuenta el origen de la producción, en este caso la ficción nacional, el número de personajes nacionales es de $85 \%$ y el de inmigrantes/extranjeros es de $15 \%$. Según estos datos, se puede decir que en la ficción nacional se da una sobrerrepresentación de los inmigrantes/extranjeros, en este caso, de 2.8 puntos porcentuales con respecto a la realidad demográfica española. Sin embargo, cuando se tiene en cuenta todos los programas analizados, independientemente del origen de la producción, apenas hay diferencia porcentual -en este caso, la diferencia es de tan solo 0.6 puntos- por lo que se puede decir que hay una ligera infra-representación que no sería muy significativa-.

Sin embargo, si tenemos en cuenta las semanas de emisión la interpretación de los resultados puede ser diferente. Así, tanto en la primera semana como en la segunda semana de análisis, el porcentaje de personajes inmigrantes/extranjeros se sitúa sobre el $9 \%$, mientras que en la tercera semana de análisis este porcentaje llega al $16 \%$. Se observa, por tanto, diferencias como muestra $\chi^{2}\left(\chi^{2}[2, N=2602]=26.67, p<\right.$ .001) y los residuos ajustados. A la vista de estos datos, se puede relativizar la afirmación de que hay una sobrerrepresentación de los inmigrantes/extranjeros en la ficción, ya que solo se ha producido en una de las semanas de análisis, en la tercera semana -del 11 de julio al 17 de julio de 2011-. Esta semana que, por diversas circunstancias -se analizó una semana del verano- fue una semana donde se emitieron muchos programas -series, fundamentalmente- de producción nacional, donde había muchos emigrantes -por ejemplo, dos capítulos de Abuela de verano, dos de Mujeres, dos de Los protegidos, etc.-.

Tabla 7. Relación entre la nacionalidad del personaje y la semana de análisis (\% columna)

\begin{tabular}{|c|c|c|c|c|}
\hline \multirow[t]{2}{*}{ Nacionalidad del personaje } & \multirow[t]{2}{*}{ Total } & \multicolumn{3}{|c|}{ Semana de análisis } \\
\hline & & Semana 1 & Semana 2 & Semana 3 \\
\hline - Autóctono/nacional & 88.4 & $90.4+$ & $90.8+$ & $83.6-$ \\
\hline - Inmigrante/extranjero & 11.6 & $9.6-$ & $9.2-$ & $16.4+$ \\
\hline $\bar{N}$ & 2602 & 1.003 & 769 & 830 \\
\hline
\end{tabular}

- Valor estadísticamente menor que el porcentaje total (análisis de los residuos tipificados corregidos).

+ Valor estadísticamente mayor que el porcentaje total (análisis de los residuos tipificados corregidos). $\left(\chi^{2}[2, N=2602]=26.67, p<.001\right)$

La hipótesis inicial trataba de averiguar si existía una infra-representación de los personajes inmigrantes en la programación de ficción emitida en el horario de prime time en televisión. Una vez analizados los datos obtenidos, tanto los globales como los nacionales, se puede afirmar que esta hipótesis no ha sido confirmada totalmente, ya que en la ficción nacional se da una sobrerrepresentación de este colectivo, aunque si no se tiene en cuenta el origen de la producción sí que hablaríamos de infrarrepresentación. Ahora bien, si se tienen en cuenta la ficción por semanas solo habría sobrerrepresentación en la última semana, pero no en las dos primeras, según los datos obtenidos en la ficción nacional.

\subsection{Hipótesis 2: Diferencias entre personajes autóctonos/nacionales e inmigrantes/extranjeros en función del tipo de personaje}


La hipótesis segunda planteó que existiría una relación entre el tipo de personaje principal, secundario o background- y la nacionalidad del personaje. De este modo cabía esperar que los personajes inmigrantes/extranjeros, en comparación con los personajes autóctonos/nacionales, ocuparían en mayor medida papeles secundarios o de background y en menor medida aparecerían como personajes principales.

El reparto de los personajes según el tipo de personaje que desempeñan en el programa de ficción estaba configurado por una mayoría de personajes de tipo background -1.600 personajes que suponen un $61.5 \%$ de la muestra total-, seguida de secundarios -681 personajes, un $26.2 \%$ - y, por último, principales -321 personajes-, un $12.3 \%$. A la hora de determinar la nacionalidad de un personaje, 2.299 personajes fueron codificados como nacionales $-88.4 \%-$ y los 299 restantes como inmigrantes/extranjeros -un $11.6 \%$-, de la muestra total independientemente del origen del programa. De los 2.299 personajes codificados como nacionales, un $60.7 \%$ -1.395 personajes- realizaban funciones de background, un 27\% -620 personajes- lo hacían de secundario y un $12.4 \%$-284 personajes- eran principales ${ }^{14}$ en la historia. En los personajes inmigrantes/extranjeros, el reparto de personajes era el siguiente: un $67.7 \%$ se codificaron como background -205 personajes- ; un $20.1 \%$ secundarios -61 personajes-; $\mathrm{y}$, por último, un $12.2 \%$-37 personajes- como principales.

Tabla 8. Relación entre la nacionalidad del personaje y tipo de personaje (\% columna)

\begin{tabular}{|c|c|c|c|}
\hline \multirow{2}{*}{$\begin{array}{ll}\text { Tipo } & \text { de } \\
\text { personaje } & \end{array}$} & \multirow[b]{2}{*}{$\%$ total } & \multicolumn{2}{|c|}{ Nacionalidad del personaje } \\
\hline & & Autóctono/nacional & Inmigrante/extranjero \\
\hline - $\quad$ Principal & 12.3 & 12.4 & 12.2 \\
\hline - Secundario & 26.2 & $27.0+$ & $20.1-$ \\
\hline - Background & 61.5 & $60.7-$ & $67.7+$ \\
\hline $\bar{N}$ & 2.602 & 2.299 & 303 \\
\hline
\end{tabular}

- Valor estadísticamente menor que el porcentaje total (análisis de los residuos tipificados corregidos).

+ Valor estadísticamente mayor que el porcentaje total (análisis de los residuos tipificados corregidos). $\left(\chi^{2}[2, N=2602]=6.90, p<.032\right)$

Para poder determinar hasta qué punto las dos variables eran independiente o no, se recurrió de nuevo al estadístico de contraste $\chi^{2}$ de Pearson. Se observó una relación estadísticamente significativa entre ambas variables $\left(X^{2}[2, N=2.602]=6.90, p<.032\right)$. El porcentaje de personajes principales era similar entre los personajes inmigrantes/extranjeros y los autóctonos/nacionales. En secundarios fue ligeramente superior -porcentualmente la diferencia es de 6.9- en personajes de origen nacional, sin embargo, los personajes inmigrantes/extranjeros ocupaban roles de background en mayor proporción que los inmigrantes/extranjeros (67.5\% versus $60.7 \%)$, por lo que esta hipótesis se vio parcialmente respaldada por los datos.

14 En la codificación, todos los personajes principales -tanto nacionales como inmigrantes/extranjeros- pudieron ser identificados, no así con algunos personajes secundarios y background, cuya nacionalidad no se pudo codificar por no estar suficientemente clara. El número de personajes no identificados en la variable nacionalidad apenas es significativa, ya que supone un $0.8 \%$ de los personajes -un $0.1 \%$ en los secundarios y un $0.7 \%$ de los personajes background-. 
Inmigración- ficción televisiva- prime time-análisis de contenido.

El papel que el personaje desempeña dentro del relato viene determinado por el número de apariciones ${ }^{15}$. De acuerdo con lo que cabría esperar, los personajes principales aparecían en cuatro ocasiones o más ${ }^{16}$ en un $97.5 \%$. En lo que se refiere a los personajes de background aparecen en una ocasión el $51.3 \%$, aunque un $20.6 \%$ de los personajes identificados como background aparecen en cuatro ocasiones o más.

Tabla 9. Relación entre el tipo de personaje y el número de apariciones (\% columna)

\begin{tabular}{|c|c|c|c|c|}
\hline \multirow{2}{*}{$\begin{array}{l}\text { Número de } \\
\text { apariciones }\end{array}$} & \multirow[b]{2}{*}{$\%$ total } & \multicolumn{2}{|c|}{ Tipo de personaje } & \multirow[b]{2}{*}{ Background } \\
\hline & & Principal & Secundario & \\
\hline - 1 ocasión & 34.8 & $1.6-$ & $11.4-$ & $51.3+$ \\
\hline - $2-3$ & 22.6 & 0.9 - & 20.1 & $27.9+$ \\
\hline $\begin{array}{l}\text { ocasiones } \\
\text { - } 4 \text { ocasiones } \\
\text { o más }\end{array}$ & 42.5 & $97.5+$ & $68.5+$ & $20.6-$ \\
\hline $\bar{N}$ & 2.623 & 321 & 683 & 1.619 \\
\hline
\end{tabular}

- Valor estadísticamente menor que el porcentaje total (análisis de los residuos tipificados corregidos). + Valor estadísticamente mayor que el porcentaje total (análisis de los residuos tipificados corregidos). $\left(\chi^{2}[2, N=2623]=945.55, p<.001\right)$

Una vez identificada la relación existente entre tipos de personaje y número de apariciones, se verificó hasta qué punto había una relación entre el número de apariciones del personaje y la nacionalidad del mismo, para poder comprobar qué personajes son los que aparecen en mayor medida en la ficción televisiva.

Se observó una relación significativa entre el número de apariciones del personaje y la nacionalidad del mismo con el parámetro de contraste $\chi^{2}$ de Pearson $\left(\chi^{2}[2, N=\right.$ $2602]=10.09, p<.018)$, de manera que los personajes autóctonos/nacionales tenían mayores probabilidades de aparecer en cuatro o más ocasiones que los inmigrantes/extranjeros, tal y como lo demuestran los siguientes datos: el $43.6 \%$ de los autóctonos/nacionales aparecían en cuatro o más ocasiones frente al 36.6\% de los inmigrantes/extranjeros. Además, éstos últimos aparecían en el $29.4 \%$ de los casos en 2-3 ocasiones, en cambio los personajes autóctonos/nacionales sólo en un $21.8 \%$.

15 El número de apariciones se codificaron de la siguiente manera: 1 = aparece en 1 ocasión; 2 = aparece en 2 ó 3 ocasiones, es decir, aparece en 2 ó 3 secuencias en todo el programa; $3=$ aparece 4 o más ocasiones durante el programa, esto es, aparece en más de 4 secuencias en todo el programa.

16 Estos datos se han calculado teniendo en cuenta la siguiente afirmación: un personaje principal deberá aparecer en 4 ocasiones o más, así como un secundario lo hará en 2-3 ocasiones y los personajes background lo harán en una ocasión. De este modo, se calculará el porcentaje teniendo en cuenta el total de apariciones de los personajes en función de cada categoría. 
Tabla 10. Relación entre la nacionalidad y el número de apariciones

\begin{tabular}{|c|c|c|c|}
\hline \multirow{2}{*}{$\begin{array}{l}\text { Número de } \\
\text { apariciones }\end{array}$} & \multirow[b]{2}{*}{$\%$ total } & \multicolumn{2}{|c|}{ Nacionalidad } \\
\hline & & Autóctono/nacional & Inmigrante/extranjero \\
\hline - 1 ocasión & 34.5 & 34.5 & 34.0 \\
\hline - 2-3 ocasiones & 22.7 & $21.8-$ & $29.4+$ \\
\hline $\begin{array}{l}\text { - } 4 \text { ocasiones o } \\
\text { más }\end{array}$ & 42.8 & $43.6+$ & $36.6-$ \\
\hline$N$ & 2.602 & 2.299 & 303 \\
\hline
\end{tabular}

- Valor estadísticamente menor que el porcentaje total (análisis de los residuos tipificados corregidos).

+ Valor estadísticamente mayor que el porcentaje total (análisis de los residuos tipificados corregidos). $\left(\chi^{2}[2, N=2602]=10.09, p<.018\right)$

\subsection{Hipótesis 3: Diferencias entre personajes autóctonos/nacionales e inmigrantes/extranjeros en función del rol narrativo}

La hipótesis tercera planteó que había una diferencia estadísticamente significativa entre la nacionalidad del personaje y su rol narrativo, por lo que se esperaba que hubiera una mayor frecuencia de personajes antagónicos o villanos, de secundarios protagónicos y de secundarios no protagónicos, y menos de protagonistas, entre los personajes inmigrantes/extranjeros, en comparación con los autóctonos/nacionales.

No se observaron diferencias estadísticamente significativas entre personajes autóctonos/nacionales e inmigrantes/extranjeros en los roles narrativos desempeñados dentro de los programas con la prueba de contraste $\chi^{2}$ de Pearson $\left(\chi^{2}\right.$ $[3, N=2602]=5.74, p=.125)$. Según los datos analizados, la hipótesis tercera no se ha visto confirmada.

Tabla 11. Relación entre la nacionalidad del personaje y rol narrativo (\% en columna)

\begin{tabular}{|c|c|c|c|}
\hline \multirow{2}{*}{ Rol narrativo } & \multirow[b]{2}{*}{$\%$ total } & \multicolumn{2}{|c|}{ Nacionalidad del personaje } \\
\hline & & Autóctono/nacional & Inmigrante/extranjero \\
\hline - Protagonista & 11.5 & 11.7 & 9.6 \\
\hline - Antagonista o villano & 6.7 & $6.3-$ & $9.6+$ \\
\hline - Secundario protagónico & 14.5 & 14.7 & 13.2 \\
\hline $\begin{array}{l}\text { - Secundario no } \\
\text { protagónico }\end{array}$ & 67.3 & 67.3 & 67.7 \\
\hline $\bar{N}$ & 2.602 & 2.299 & 303 \\
\hline
\end{tabular}

- Valor estadísticamente menor que el porcentaje total (análisis de los residuos tipificados corregidos).

+ Valor estadísticamente mayor que el porcentaje total (análisis de los residuos tipificados corregidos). $\left(\chi^{2}[2, N=2602]=5.74, p=.125\right)$

\subsection{Hipótesis 4: Diferencias entre personajes autóctonos/nacionales e inmigrantes/extranjeros en función de su cualificación y estatus profesional}

Esta hipótesis analizó la cualificación y el estatus profesional de los personajes, indicando que los personajes inmigrantes/extranjeros, en comparación con los personajes autóctonos/nacionales, tendrían un menor nivel de estudios, un menor nivel socio-económico y desempeñarían profesiones de menor cualificación. 
Con respecto al nivel de estudios, se observaron diferencias estadísticamente significativas $\left(\chi^{2}[5, N=2602]=76.52, p<.001\right)$, ya que un porcentaje muy elevado de personajes inmigrantes/extranjeros quedaban sin definir en cuanto a su nivel de estudios $(59.1 \%)$, algo que no sucedía con la misma intensidad entre los personajes autóctonos/nacionales (37.5\%). Además, había un mayor porcentaje de analfabetos entre los inmigrantes/extranjeros (2.3\%) que entre los personajes autóctonos/nacionales $(0.4 \%)$, resultado que también se repetía en los personajes sin estudios $-4 \%$ de los inmigrantes/extranjeros frente al $2.6 \%$ de los autóctonos/nacionales -. Sin embargo, en el resto de las categorías -estudios primarios, secundarios y universitarios- era mayor el porcentaje en los personajes autóctonos/nacionales frente a los inmigrantes/extranjeros.

Tabla 12. Relación entre la nacionalidad del personaje y nivel de estudios (\% en columna)

\begin{tabular}{|c|c|c|c|}
\hline \multirow[t]{2}{*}{ Nivel de estudios } & \multirow[t]{2}{*}{$\%$ total } & \multicolumn{2}{|c|}{ Nacionalidad del personaje } \\
\hline & & Autóctono/nacional & Inmigrante/extranjero \\
\hline - $\quad$ No se puede identificar & 40 & $37.5-$ & $59.1+$ \\
\hline - Analfabeto & 0.7 & $0.4-$ & $2.3+$ \\
\hline - Sin estudios & 2.8 & 2.6 & 4.0 \\
\hline - $\quad$ Primarios & 7.5 & $8.0+$ & $4.3-$ \\
\hline - Secundarios & 18.3 & $19.2+$ & $11.2-$ \\
\hline - Universitarios & 30.7 & $32.3+$ & $19.1-$ \\
\hline$N$ & 2.602 & 2.299 & 303 \\
\hline
\end{tabular}

- Valor estadísticamente menor que el porcentaje total (análisis de los residuos tipificados corregidos).

+ Valor estadísticamente mayor que el porcentaje total (análisis de los residuos tipificados corregidos). $\left(\chi^{2}[5, N=2602]=76.52, \mathrm{p}<.001\right)$

Se observó una asociación estadísticamente significativa entre la nacionalidad del personaje y el nivel económico $\left(\chi^{2}[3, N=2602]=6.96, p<.073\right)$. Los personajes inmigrantes/extranjeros aparecían con mayor frecuencia con un nivel socioeconómico bajo (12.2\%) que los personajes autóctonos/nacionales (8.1\%), aunque en el resto de las categorías presentaban resultados similares, tal y como se puede observar en la tabla.

Tabla 13. Relación entre la nacionalidad del personaje y nivel socio-económico (\% columna)

\begin{tabular}{|c|c|c|c|}
\hline \multirow[t]{2}{*}{ Nivel socio-económico } & \multirow[t]{2}{*}{$\%$ total } & \multicolumn{2}{|c|}{ Nacionalidad del personaje } \\
\hline & & Autóctono/nacional & Inmigrante/extranjero \\
\hline $\begin{array}{ll}\text { - No se puede } \\
\text { identificar }\end{array}$ & 0.8 & 0.9 & 0.3 \\
\hline - $\quad$ Bajo & 8.6 & $8.1-$ & $12.2+$ \\
\hline - $\quad$ Medio & 78.8 & 79.1 & 76.9 \\
\hline - $\quad$ Alto & 11.8 & 11.9 & 10.6 \\
\hline$N$ & 2.602 & 2.299 & 303 \\
\hline
\end{tabular}

- Valor estadísticamente menor que el porcentaje total (análisis de los residuos tipificados corregidos).

+ Valor estadísticamente mayor que el porcentaje total (análisis de los residuos tipificados corregidos). $\left(X^{2}[3, \mathrm{~N}=2602]=6.96, \mathrm{p}<.073\right)$ 
Para finalizar, se analizó la relación entre la nacionalidad del personaje y la ocupación laboral que desempeñan en la ficción. Se apreció una asociación estadísticamente significativa en función de la ocupación laboral con la prueba de contraste $X^{2}$ de Pearson $\left(X^{2}[17, N=2602]=103.72, p<.001\right)$. Así, hay un mayor porcentaje de personajes autóctonos/nacionales que inmigrantes/extranjeros a los que no se les pudo identificar la profesión -16.2\% frente al 10.5\%-. En profesiones como director y profesional y estudiante había un mayor porcentaje de personajes autóctonos/nacionales que de inmigrantes/extranjeros, sin embargo, el porcentaje es considerablemente más alto entre los inmigrantes/extranjeros que los autóctonos/nacionales en categorías como trabajador no cualificado y, especialmente, en actividades de tipo delictivo, tal y como puede verse en la tabla que se adjunta.

A modo de resumen, los personajes inmigrantes/extranjeros sí tenían un nivel de estudios bajo y desempeñaban profesiones con menor cualificación. Además, presentaban un nivel socioeconómico bajo, por lo que, en base a estos resultados, se puede concluir que la hipótesis cuarta se vio confirmada por los datos.

Tabla 14. Relación entre la nacionalidad del personaje y ocupación laboral o actividad principal (\% columna)

\begin{tabular}{|c|c|c|c|}
\hline \multirow[t]{2}{*}{ Ocupación laboral o actividad principal } & \multirow[t]{2}{*}{$\%$ Total } & \multicolumn{2}{|c|}{ Nacionalidad del personaje } \\
\hline & & Autóctono/nacional & Inmigrante/extranjero \\
\hline - $\quad$ No se puede identificar & 15.6 & $16.2+$ & $10.5-$ \\
\hline $\begin{array}{l}\text { - No tiene una ocupación profesional } \\
\text { estable }\end{array}$ & 0.6 & 0.5 & 1 \\
\hline - Director y profesional & 4.4 & $4.7+$ & $2-$ \\
\hline - Técnico y cuadro medio & 12.7 & 13 & 10.6 \\
\hline - Pequeño comerciante & 2.4 & 2.5 & 1.7 \\
\hline - Empleado de oficina y servicios & 2.4 & $2.7+$ & $0.7-$ \\
\hline - Trabajador cualificado & 3.9 & 3.8 & 4.3 \\
\hline - Trabajador no cualificado & 5.3 & $4.9-$ & $8.6+$ \\
\hline $\begin{array}{l}\text { - Agricultor, ganadero, pesca (sector } \\
\text { primario) }\end{array}$ & 0.6 & 0.7 & 0.3 \\
\hline - Religioso & 1.3 & 1.4 & 0.3 \\
\hline - Policía y/o militar & 23.6 & 22.1- & $34.7+$ \\
\hline - Jubilado y/o pensionista & 1.2 & 1.3 & 0.3 \\
\hline - Parado o desempleado & 1 & 1.1 & 0 \\
\hline - Estudiante & 9.6 & $10.5+$ & $3-$ \\
\hline - Trabajo doméstico no remunerado & 1.4 & $1.6+$ & - \\
\hline $\begin{array}{l}\text { - Deportista, artista o profesional del } \\
\text { espectáculo }\end{array}$ & 3.3 & 3.3 & 3.3 \\
\hline $\begin{array}{l}\text { Se dedica a actividades de tipo } \\
\text { delictivo }\end{array}$ & 6.6 & $5.6-$ & $14.5^{+}$ \\
\hline $\begin{array}{l}\text { - Otra profesión (no contemplada en el } \\
\text { listado) }\end{array}$ & 3.9 & 3.9 & 4.3 \\
\hline
\end{tabular}

- Valor estadísticamente menor que el porcentaje total (análisis de los residuos tipificados corregidos).

+ Valor estadísticamente mayor que el porcentaje total (análisis de los residuos tipificados corregidos).

$\chi^{2}[17, \mathrm{~N}=2602]=103.72, \mathrm{p}<.001$ 


\subsection{Hipótesis 5: Diferencias entre personajes autóctonos/nacionales e inmigrantes/extranjeros en la caracterización psico-social}

La última de las hipótesis analizó las diferencias existentes entre los personajes inmigrantes/extranjeros, en comparación con los autóctonos/nacionales, en la manifestación de comportamientos violentos, victimización, problemas de salud, temas de conversación y rasgos de personalidad. Se esperaba encontrar que los personajes inmigrantes/extranjeros protagonizarían más actos violentos y también se vieran implicados en actos violentos siendo víctimas de estos, presentarían mayores problemas de salud, su riqueza conversacionales sería menor y presentarían rasgos de conversación negativos. Para poder contrastar esta hipótesis se realizó un análisis multivariado de la varianza (MANOVA), en el que la variable independiente fue la nacionalidad del personaje -autóctonos/nacionales versus extranjero/inmigrante- y las variables dependientes fueron los índices creados de comportamientos violentos, victimización, problemas de salud, riqueza conversacional y los dos factores de personalidad -atributos de personalidad positivos y atributos de personalidad negativos-.

Tabla 15. Diferencias entre personajes autóctonos/nacionales e inmigrantes/extranjeros en comportamientos violentos, victimización, problemas de salud, riqueza conversacional y atributos de personalidad (análisis multivariado de la varianza, MANOVA)

\begin{tabular}{|c|c|c|c|c|c|c|}
\hline \multirow[t]{2}{*}{ Variables (índices) } & \multicolumn{2}{|c|}{ Nacionalidad } & \multirow[t]{2}{*}{$F$} & \multirow[t]{2}{*}{$g l$} & \multirow[t]{2}{*}{$p$} & \multirow[t]{2}{*}{$\eta_{\mathrm{p}}^{2}$} \\
\hline & $\begin{array}{l}\text { Autóctono/ } \\
\text { nacional }\end{array}$ & $\begin{array}{l}\text { Inmigrante/ex } \\
\text { tranjero }\end{array}$ & & & & \\
\hline $\begin{array}{ll}- & \text { Violencia } \\
& \text { [rango teórico: 0-5] }\end{array}$ & $\begin{array}{c}0.65 \\
(1.08)\end{array}$ & $\begin{array}{c}1.32 \\
(1.30)\end{array}$ & 87.34 & 1,2208 & .000 & .038 \\
\hline $\begin{array}{l}\text { - Victimización } \\
\text { [rango teórico: 0-5] }\end{array}$ & $\begin{array}{c}0.54 \\
(0.96)\end{array}$ & $\begin{array}{c}0.54 \\
(0.97)\end{array}$ & 0.00 & 1,2208 & .991 & .000 \\
\hline $\begin{array}{l}\text { - Problemas de salud } \\
\text { [rango teórico: 0-5] }\end{array}$ & $\begin{array}{c}0.17 \\
(0.45)\end{array}$ & $\begin{array}{c}0.20 \\
(0.46)\end{array}$ & 1.30 & 1,2208 & .254 & .001 \\
\hline $\begin{array}{l}\text { - Riqueza conversacional } \\
\text { [rango teórico: 0-15] }\end{array}$ & $\begin{array}{c}3.59 \\
(2.39)\end{array}$ & $\begin{array}{c}3.22 \\
(2.28)\end{array}$ & 5.94 & 1,2208 & .015 & .003 \\
\hline $\begin{array}{l}\text { - Atributos de personalidad } \\
\text { positivos } \\
\text { [rango teórico: } 1-3]\end{array}$ & $\begin{array}{l}2.17 \\
(0.61)\end{array}$ & $\begin{array}{c}1.89 \\
(0.61)\end{array}$ & 52.60 & 1,2208 & .000 & .023 \\
\hline $\begin{array}{l}\text { Atributos de personalidad } \\
\text { negativos } \\
\text { [rango teórico: } 1-3 \text { ] }\end{array}$ & $\begin{array}{c}1.21 \\
(0.39)\end{array}$ & $\begin{array}{c}1.50 \\
(0.52)\end{array}$ & 116.06 & 1,2208 & .000 & .050 \\
\hline$N$ & 1.932 & 278 & & & & \\
\hline
\end{tabular}

Nota.- Para cada variable se indica la media y la desviación típica entre paréntesis. 
Se observó que existían diferencias significativas a nivel multivariado (Lambda de Wilks $\left.=.93, F_{\text {multivariada }}[6,2203]=27.60, p<.001, \eta_{\mathrm{p}}^{2}=.070\right) . \mathrm{Al}$ analizar las diferencias entre personajes autóctonos/nacionales e inmigrantes/extranjeros a nivel univariado, se observaron diferencias significativas en el índice de rasgos negativos de personalidad $\left(F[1,2208]=116.03, p<.000, \eta_{p}^{2}=.050\right)$, en el índice de comportamientos violentos $\left(F[1,2208]=87.35, p<.001, \eta_{p^{2}}=.038\right)$, en riqueza conversacional $\left(F[1,2208]=5.94, p<.017, \eta_{\mathrm{p}}{ }^{2}=.003\right) \mathrm{y}$ en el indicador de atributos positivos de personalidad $\left(F[1,2208]=52.60, p<.001, \eta_{p}{ }^{2}=.023\right)$. No se observaron diferencias estadísticamente significativas en el índice de victimización $(F[1,2208]=$ $\left..00, p=.991, \eta_{\mathrm{p}}^{2}=.000\right)$ ni en los problemas de salud $\left(F[1,2208]=1.30, p=.244, \eta_{p^{2}}=\right.$ $.001)$.

Si se comparaban ambos grupos en todas las variables, los personajes extranjeros/inmigrantes puntuaban más alto que los personajes autóctonos/nacionales en el índice de comportamiento violento, en el índice de problemas de salud y en el índice de atributos de personalidad negativos. En cambio, los personajes autóctonos/nacionales puntuaban más alto en atributos de personalidad positivos y en riqueza conversacional. Cuando se analizaron las diferencias específicas en problemas de salud, en la única variable que se apreciaron diferencias estadísticamente significativas fue en el consumo de alcohol $\left(\chi^{2}[1, N=\right.$ $2602]=6.11, p<.013)$, ya que el porcentaje de personajes que consumía alcohol era más frecuente entre los personajes inmigrantes/extranjeros $(13.9 \%)$ que entre los autóctonos/nacionales $(9.4 \%)$.

En cuanto a las diferencias específicas en temas de conversación asociados con la nacionalidad, se observó que los personajes autóctonos/nacionales puntuaban, por lo general, más en todas las variables conversacionales que los inmigrantes/extranjeros. Los personajes autóctonos nacionales hablaban más de amor $\left(29.3 \%\right.$ versus $22.1 \%$; $\chi^{2}$ $[1, N=2602]=6.84, p<.009)$, violencia $\left(39.4 \%\right.$ versus $32 \% ; \chi^{2}[1, N=2602]=6.18, p<$ $.013)$, sexo $\left(17.2 \%\right.$ versus $\left.9.6 \% ; \chi^{2}[1, N=2602]=11.36, p<.001\right)$ y familia $(42.4 \%$ versus 28.7\%; $\left.\chi^{2}[1, N=2602]=20.66, p<.001\right)$, por ejemplo, que los inmigrantes/extranjeros, pero estos trataron más veces temas como diferencias sociales $\left(8.3 \%\right.$ versus $\left.4.8 \% ; \chi^{2}[1, N=2602]=6.33, p<.012\right)$, trabajo $(86.8 \%$ versus $\left.68.6 \% ; \chi^{2}[1, N=2602]=43.01, p<.001\right)$, política $\left(27.1 \%\right.$ versus $12 \% ; \chi^{2}[1, N=2602]=$ $51.15, p<.001)$ e inmigración $\left(6.6 \%\right.$ versus $\left.2.8 \% ; \chi^{2}[1, N=2602]=12.48, p<.001\right)$.

Tabla 16. Relación entre la nacionalidad del personaje y temas de conversación tratados (\% columna)

\begin{tabular}{|c|c|c|c|c|c|}
\hline \multirow{2}{*}{$\begin{array}{l}\text { Temas de } \\
\text { conversación }\end{array}$} & \multicolumn{2}{|c|}{ Nacionalidad del personaje } & \multirow[b]{2}{*}{$x^{2}$} & \multirow[b]{2}{*}{$g l$} & \multirow[b]{2}{*}{$p$} \\
\hline & Autóctono/nacional & Inmigrante/extranjero & & & \\
\hline - Amor & 29.3 & 22.1 & 6.84 & 1 & .009 \\
\hline - Violencia & 39.4 & 32 & 6.18 & 1 & .013 \\
\hline - Amistad & 20.4 & 13.9 & 7.25 & 1 & .007 \\
\hline - $\quad$ Sexo & 17.2 & 9.6 & 11.36 & 1 & .001 \\
\hline - Dinero & 30.9 & 28.7 & .59 & 1 & .593 \\
\hline $\begin{array}{l}\text { Diferencias } \\
\text { sociales }\end{array}$ & 4.8 & 8.3 & 6.33 & 1 & .012 \\
\hline - Trabajo & 68.6 & 86.8 & 43.01 & 1 & .000 \\
\hline - Medio ambiente & 4.7 & 5.6 & .43 & 1 & .508 \\
\hline
\end{tabular}


Inmigración- ficción televisiva- prime time-análisis de contenido.

\begin{tabular}{llrrrr} 
- Salud & 37.1 & 23.1 & 22.79 & 1 & .000 \\
- Educación & 11.1 & 8.3 & 2.25 & 1 & .134 \\
- Familia & 42.4 & 28.7 & 20.66 & 1 & .000 \\
- Política & 12 & 27.1 & 51.15 & 1 & .000 \\
- Deporte & 6.9 & 6.6 & .03 & 1 & .860 \\
- Racismo & 1.6 & 1.7 & .01 & 1 & .912 \\
- Inmigración & 2.8 & 6.6 & 12.48 & 1 & .000 \\
\hline \multicolumn{1}{c}{$\boldsymbol{N}$} & $\mathbf{2 . 2 9 9}$ & $\mathbf{3 0 3}$ & & & \\
\hline
\end{tabular}

- Valor estadísticamente menor que el porcentaje total (análisis de los residuos tipificados corregidos).

+ Valor estadísticamente mayor que el porcentaje total (análisis de los residuos tipificados corregidos).

Cuando se analizaron las diferentes variables de personalidad, a grandes rasgos los personajes autóctonos/nacionales puntuaban más alto en los rasgos positivos, frente a los inmigrantes/extranjeros que lo hacían en los negativos. Analizando las diferencias específicas, los personajes inmigrantes/extranjeros puntuaban más alto que los personajes autóctonos/nacionales en los siguientes rasgos: agresivo $(t(350.94)$ $=-9.03, p<.001)$, conflictivo $(t(341.12)=-9.68, p<.001)$, desleal o traicionero $(t(356.05)$ $=-5.44, p<.001)$ e intolerante $(t(336.57)=-5.52, p<.001)$. Por el contrario, los personajes autóctonos/nacionales puntuaban más alto en amistoso $(t(2600)=3.53, p$ $<.001)$, bueno o de buen corazón $(t(413.56)=3.73, p<.001)$ y abierto $(t(418.87)=2.74$, $p<.006)$ que los personajes inmigrantes/extranjeros.

A modo de resumen, los personajes inmigrantes/extranjeros, en la muestra analizada, protagonizaron un mayor número de actos violentos, estaban representados con rasgos de personalidad negativos, menos positivos, y con un nivel conversacional menor. En conjunto, los resultados obtenidos suponen una confirmación de la última de las hipótesis.

\section{CONCLUSIONES}

El estudio realizado viene a completar los estudios precedentes realizados en España, ya que además de analizar una muestra de población muy amplia de programas, es muy elevado el número de personajes analizados. El hecho de contar con una muestra de análisis lo suficientemente representativa permite que los resultados obtenidos sean extrapolables y generalizables, lo que permite extraer conclusiones reveladoras. Una de las primeras premisas a analizar es la representación de los personajes inmigrantes en la ficción emitida en horario de prime time. Si tenemos en cuenta las tres semanas de análisis independientemente del origen de la emisión a analizar, los personajes inmigrantes/extranjeros están ligeramente infrarrepresentación de los personajes inmigrantes en la ficción emitida en horario de prime time. Sin embargo, cuando se analizan los datos de la ficción nacional, los personajes inmigrantes/extranjeros están sobrerrepresentados. Cuando se ha analizado con detenimiento los datos de sobrerrepresentación, se ha observado que se ha debido a una semana muy concreta del año, la del verano, donde la programación analizada era diferente a la del resto del año, con series y largometrajes nacionales donde había una gran representación de inmigrantes -por ejemplo, en la serie Mujeres aparecen de forma habitual dos personajes protagónicos inmigrantes y 
en los dos capítulos analizados esta cifra se elevó a cuatro, como se analizaron dos capítulos de la serie, los personajes inmigrantes/extranjeros en esta ficción fueron ocho, una cifra muy superior a la que se da habitualmente en las series españolas, donde, por ejemplo, en Ángel o demonio no había ni un solo personaje inmigrante. Esto mismo ha sucedido con varias series más, como Abuela de verano-. Sin embargo, si se extrae del análisis esta semana, las cifras varían y se observa una infrarrepresentación de los personajes inmigrantes/extranjeros en la ficción nacional. Que los inmigrantes/extranjeros que viven en España no estén representados en la ficción es importante, ya que no mostrar a todos los grupos sociales y étnicos que conforman el país, supone que hay un porcentaje de la sociedad que no se ve reflejado en la televisión nacional: no aparecen sus problemáticas, ni sus rutinas de vida, ni sus realidades... Además, no solo no están reflejados sino que no se muestra diversidad en la ficción nacional al no estar representados las diferentes nacionalidades que conviven en España actualmente al estar representados en la ficción, de forma mayoritaria, personajes de origen nacional.

Es más revelador, si cabe, que cuando las ficciones incorporan personajes inmigrantes/extranjeros la imagen que de ellos se da esté sesgada o estereotipada. Por ejemplo, según reflejan los datos de este estudio, los personajes inmigrantes/extranjeros realizan en su mayoría papeles de background, por lo que apenas están representados debido a su escasa aparición y peso en la historia. Cuando estos personajes aparecen en los programas de ficción, tienen mayores probabilidades de ser analfabetos, de realizar trabajos no cualificados y sin ocupación estable que los personajes autóctonos/nacionales. Suelen desempeñar, además, roles de villanos por lo que se ven envueltos en tramas donde hay mayor presencia de actos violentos. Además, su nivel socioeconómico es más bajo que el de los personajes autóctonos/nacionales. Al ser personajes de tipo background no intervienen en muchas tramas de los programas de ficción, y en consecuencia, no participan en muchos diálogos por lo que su riqueza conversacional es menor que la que desarrollan los autóctonos/nacionales. A todo esto, se debe añadir que los personajes inmigrantes/extranjeros están definidos con más atributos negativos de personalidad: son más agresivos, conflictivos, desleales o traicioneros e intolerantes que los personajes autóctonos/nacionales.

Los resultados de este estudio son convergentes con los realizados en estas áreas y con estudios previos desarrollados en Estados Unidos en relación con la representación de las minorías étnicas en la ficción televisiva (Mastro y Greenberg, 2000; Mastro y Behm-Morawitz, 2005) y con un estudio ${ }^{17}$ realizado por Igartua, Barrios y Ortega (2012).

Por un lado se puede hablar de la baja presencia de personajes inmigrantes/extranjeros en la ficción. La ausencia de diversidad en la ficción televisiva puede condicionar su visibilidad o vitalidad social ya que existe un porcentaje de población de España que no solo no aparece representada sino que además es invisible para cierta población que, por diversos motivos, puede no tener

17 En este estudio la muestra fue de 1.345 personajes analizados, extraídos de programas de ficción emitidos en España en horario de prime time en el año 2010. 
contacto en su vida diaria con personas inmigrantes/extranjeras y cuyo único medio de contacto con este sector de población sea a través de los medios de comunicación, especialmente la televisión que es el medio que mayor nivel de penetración y accesibilidad tiene. Esta falta de visibilidad mediática hace más difícil que se establezca un contacto vicario parasocial de la población autóctona con personajes de otros orígenes nacionales que tienen una presencia destacable en la sociedad española (Harwood y Anderson, 2002 y Ortiz y Harwwod, 2007). Si a esto añadimos que cuando aparecen, la imagen de los inmigrantes/extranjeros suele ser estereotípica y negativa, puede dar lugar a que se refuercen o asimilen actitudes prejuiciosas hacia los inmigrantes, ya que el espectador que no tenga ningún tipo de contacto con inmigrantes/extranjeros en su vida diaria puede llegar a pensar que todos los inmigrantes/extranjeros son tal y como aparecen reflejados en la pantalla: analfabetos, delincuentes, conflictos, violentos... El papel que pueden desempeñar los medios puede ser el contrario, esto es, no fomentar y mantener el prejuicio, sino contribuir a cambiar las actitudes y creencias sobre la inmigración reflejando, por ejemplo, otros modelos de personajes inmigrantes/extranjeros, además de fomentar el contacto vicario que, tal y como se ha demostrado, puede repercutir positivamente en la reducción del prejuicio y, por tanto, favorecer el establecimiento de relaciones más armoniosas entre ciudadanos de diferentes orígenes étnicos y nacionales (Müller, 2009; Igartua, 2010; Park, 2012). De este modo, convendría reflejar en los relatos ficcionales interacciones o contactos positivos entre los personajes autóctonos/nacionales -el endogrupo- y los personajes inmigrantes/extranjeros -el exogrupo-, de manera que se contribuirá, gracias a los programas de ficción, a reducir la percepción negativa que se tiene sobre los inmigrantes/extranjeros, que son percibidos por la sociedad como una amenaza para el grupo, fomentando la mejoría de las relaciones entre ambos grupos. Interacciones positivas, donde se desarrollen relaciones íntimas -de amistad o de pareja- o relaciones de igualdad son algunos ejemplos de narraciones que los programas de ficción deberían mostrar. Sería labor de los profesionales del mundo audiovisual realizar estos cambios a la hora de crear personajes, pues tanto los creadores -fundamentalmente, guionistascomo los realizadores, productores ejecutivos, actores... son los máximos responsables de la imagen que se da de los inmigrantes en la ficción. Estudios como el que aquí se presenta pretenden ayudar a estos profesionales en el proceso de creación de personajes, puesto que se debería incorporar, tal y como se ha hecho en los medios informativos, una serie de recomendaciones para los profesionales a la hora de informar sobre la inmigración. Además, habría que concienciar a los futuros guionistas sobre la importancia de mostrar la diversidad en la ficción audiovisual. 


\section{REFERENCIAS}

AIMC (2012). Resumen general Estudio General de Medios. Madrid: Asociación para la Investigación de los Medios de Comunicación. Disponible en http:// www.aimc.es

BARDIN, L. (1996). Análisis de contenido. Madrid: Ediciones Akal.

BRADER, T., VALENTINO, N. A. y SUHAY, E. (2008). What triggers public opposition to immigration? Anxiety, group cues, and immigration threat, American Journal of Political Science, vol. 52, $\mathrm{n}^{\mathrm{o}} 4$, 959-978.

CEA D'ANCONA, M a A. (2004). La activación de la xenofobia en España. ¿Qué miden las encuestas?, Colección Monografías, $\mathrm{n}^{\circ}$ 210, Madrid: Centro de Investigaciones Sociológicas/Siglo XXI.

DÍEZ NICOLÁS, J. (2004). El Dilema de la Supervivencia. Los españoles ante el Medio Ambiente. Madrid: Ed. Obra Social Caja Madrid.

DIXON, T. L. y LINZ, D. (2000). Overrepresentation and underrepresentation of African Americans and Latinos as lawbreakers on television news, Journal of Communication, vol. 50, $\mathrm{n}^{\circ}$ 2, 131-154.

DOMKE, D., MCCOY, K. y TORRES, M. (1999). News media, racial perceptions and political cognition. Communication Research, 26 (5), 570-607.

ENTMAN, R. (1992). Blacks in the news: television, modern racism and cultural change. Journalism Quarterly, 69 (2), 341-361.

ESTÉBANEZ CALDERÓN, D. (2002). Diccionario de términos literarios. Madrid: Akal.

GALÁN, E. (2006). La representación de los inmigrantes en la ficción televisiva en España. Propuesta para un análisis de contenido. El Comisario y Hospital Central. Revista Latina de Comunicación Social, 61. Disponible en http://www.ull.es/publicaciones/latina/200608galan.htm

GREENBERG, B. S., MASTRO, D. y BRAND, J. E. (2002) Minorities and the mass media: Television into the 21st century. En J. BRYANT y D. ZILLMANN (Eds.), Media effects: advances in theory and research (pp. 333-351). Hillsdale, NJ: Lawrence Erlbaum Associates.

HARWOOD, J. y ANDERSON, K. (2002). The presence and portrayal of social groups on prime-time television. Communication Reports, 15 (2), 81-97. 
Inmigración- ficción televisiva- prime time-análisis de contenido.

IGARTUA, J. J. (2006). Métodos cuantitativos de investigación en comunicación. Barcelona: Bosch.

IGARTUA, J. J. (2010). Identification with characters and narrative persuasion through fictional feature films. Communications. The European Journal of Communication Research, 35(4), 347-373.

IGARTUA, J. J., BARRIOS, I. M. y ORTEGA, F. (2012). Analysis of the Image of Immigration in Prime Time Television Fiction. Comunicación y sociedad, 2, 5-28.

IGARTUA, J. J. y CHENG, L. (2009). Moderating effect of group cue while processing news on immigration. Is framing effect a heuristic process?. Journal of Communication, 59(4), 726-749.

IGARTUA, J. J., CHENG, L., MORAL, F., FERNÁNDEZ, I., FRUTOS, F. J., GÓMEZISLA, J. y OTERO, J. A. (2008). Encuadrar la inmigración en las noticias y sus efectos socio-cognitivos. Palabra Clave, 11(1), 87-107.

IGARTUA, J. J., MORAL, F. y FERNÁNDEZ, I. (2011). Cognitive, attitudinal and emotional effects of the news frame and group cues on processing news about immigration. Journal of Media Psychology, 23(4), 174-185.

IGARTUA, J. J., MUÑIZ, C. y CHENG, L. (2005). La inmigración en la prensa española. Aportaciones empíricas y metodológicas desde la teoría del encuadre noticioso, Migraciones, vol. 17, 143-181.

IGARTUA, J. J., MUÑIZ, C., OTERO, J. A. y DE LA FUENTE, M. (2007). El tratamiento informativo de la inmigración en los medios de comunicación españoles. Un análisis de contenido desde la Teoría del Framing. Estudios sobre el Mensaje Periodístico, 13, 91-110.

INE (2013). Cifras de Población a 1 de enero de 2013 - Estadística de Migraciones 2012 a 8 de julio de 2013. Nota de prensa. Instituto Nacional de Estadística, Madrid, 2013. Disponible en: http://www.ine.es/prensa/np788.pdf

KOEMAN, J., PEETERS, A. y D'HAENES, L. (2007). Diversity Monitor 2005. Diversity as a quality aspect of television in the Netherlands. Communications, 32, 97-121.

KRIPPENDORFF, K. (1990). Metodología de análisis de contenido. Teoría y práctica. Barcelona: Paidós Comunicación.

LACALLE, C. (2004). Comunicación y diversidad cultural. En Fórum Barcelona 2004. Disponible en: www.forumben2004.org/ 
LACALLE, C. (2008). El discurso televisivo sobre la inmigración. Ficción y construcción de identidad. Barcelona: Ediciones Omega.

MASTRO, D. y BEHM-MORAWITZ, E. (2005). Latino representation on primetime television. Journalism and Mass Communication Quarterly, 82(1), 110-130.

MASTRO, D. y GREENBERG, B. S. (2000). The portrayal of racial minorities on prime time television. Journal of Broadcasting and Electronic Media, 44(4), 690-703.

MÜLLER, F. (2009). Entertainment anti-racism. Multicultural television drama, identification and perceptions of ethnic threat. Communications. European Journal of Communication Research, 34(3), 239-256.

MUÑIZ, C. e IGARTUA, J. J. (2004). Información noticiosa sobre la inmigración en los medios de comunicación. Un análisis de la prensa y televisión españolas. En J. LATORRE, A. VARA y M. DÍAZ (Eds.), Ecología de la televisión: tecnología, contenidos y desafíos empresariales (pp. 281-290). Pamplona: Eunate.

NEUENDORF, K. A. (2002). The content analysis guidebook. Thousand Oaks, CA: Sage.

ORTIZ, M., y HARWOOD, J. (2007). A social cognitive theory approach to the effects of mediated intergroup contact on intergroup attitudes. Journal of Broadcasting and Electronic Media, 51(4), 615-631.

PARK, S. Y. (2012). Mediated intergroup contact: concept explication, synthesis, and application. Mass Communication and Society, 15(1), 136-159.

POTTER, W. (1994). Cultivation theory and research. Journalism Monographs, 147, 13.

ROMER, D., JAMIESON, K. H. y DE COTEAU, N. J. (1998). The treatment of persons of color in local television news. Ethnic blame discourse or realistic group conflict?, Communication Research, 25(3), 286-305.

RUIZ COLLANTES, X., FERRÉS, J., OBRADORS, M., PUJADAS, E. y PÉREZ, O. (2006). La imatge pública de la immigració a les sèries de televisió. Quaderns del CAC, n $^{\circ} 23-24,103-126$.

SEITER, E. (1986). Stereotypes and the media: a re-evaluation. Journal of Communication, 36(4), 14-26.

VAN DIJK, T. A. (1989). Race, riots and the press. An analysis of editorials in the British press about the 1985 disorders, Gazette, n 43, 229-253.

VAN DIJK, T. A. (1997). Racismo y análisis crítico de los medios. Paidós: Barcelona. 
Inmigración- ficción televisiva- prime time-análisis de contenido.

VAN DIJK, T. A. (2003). Ideología y discurso. Barcelona: Gedisa.

VAN GORP, B. (2005). Where is the frame? Victims and intruders in the Belgian press coverage on the asylum issue, European Journal of Communication, vol. 20, $\mathrm{n}^{\circ} 4,484-$ 507. 